\title{
Preferência dos investidores em relação ao perfil econômico- financeiro das empresas participantes do ISE: revisão sistemática
}

\begin{abstract}
A inserção da temática Sustentabilidade no contexto empresarial é estabelecida a partir dos elementos voltados ao aspecto econômico, da dimensão social e ambiental como sendo relevantes à configuração social. A adoção de práticas sustentáveis empresariais parte de demandas de cunho social, mas também das preferências dos investidores, que buscam aplicar seus recursos em empreendimentos julgados rentáveis. Portanto, considerando a relevância das discussões que envolvem a Sustentabilidade e as suas decorrências no mercado, a presente pesquisa buscou analisar e conhecer a preferência dos investidores em relação ao perfil econômico-financeiro das empresas participantes do índice de Sustentabilidade Empresarial (ISE) da BM\&F Bovespa. Para tanto, optou-se pelo desenvolvimento de uma revisão sistêmica de cunho quantitativo das publicações da ANPAD dos últimos dez anos, considerando o período de 2005 a 2014 . As pesquisas abordam, em unanimidade, o ISE, que mensura as atividades e o desempenho das empresas de capital aberto que empreendem ações com foco na articulação dos aspectos econômico, social e ambiental. Os resultados apontam que há estudos que sinalizam positivamente para a utilização do Índice de Sustentabilidade Empresarial como elemento de evidenciação de ações voltadas à sustentabilidade, ressaltando que sua adoção reverteu em benefícios positivos à empresa. Outros indicam que não podem ser aferidas vantagens relacionadas à melhor visibilidade da empresa no mercado pela simples utilização do Índice de Sustentabilidade Empresarial, pois as demonstrações revelam que, pela contraposição das tendências e preferências moldadas pelo sistema econômico, não há evidências que fundamentem tal posição.
\end{abstract}

Palavras-chave: Sustentabilidade; Índice de Sustentabilidade Empresarial; BM\&F Bovespa; Preferência dos Investidores.

\section{Investors' preference for the economic of the companies participating in the ISE:Systematic review}

\begin{abstract}
The inclusion of the subject Sustainability in the business context is established from a need to consider besides those focused on the economic aspect, the social and environmental dimension as relevant social setting. The implication of the adoption of sustainable practices by organizations of demands of a social, but also the preferences of investors seeking to invest their funds in profitable ventures judged. Therefore, considering the relevance of discussions involving the Sustainability and its consequences in the market, the present study sought to analyze and know the preference of investors in relation to the economic and financial profile of the companies participating in the Corporate Sustainability Index (ISE) of BM \& F Bovespa. To this end, we opted for the development of a systemic review of the quantitative nature of publications ANPAD the last ten years, considering the period from 2005 to 2014 . The research approach, unanimously, the ISE, which measures the activities and performance of public companies that undertake actions focused on articulation of economic, social and environmental aspects. The results show that there are studies that indicate positively to the use of the Corporate Sustainability Index as disclosure element of actions aimed at sustainability, highlighting that its adoption reversed in positive benefits to the company. Others point that can not be measured benefits related to better visibility of the company in the market for the simple use of the Corporate Sustainability Index as the demonstrations show that, by contrast trends and preferences shaped by the economic system, there is no evidence to substantiate such a position.
\end{abstract}

Keywords: Sustainability; Corporate Sustainability Index; BM\&F Bovespa; Investor Preference.

Topic: Indicadores de Sustentabilidade

Reviewed anonymously in the process of blind peer.

Edson Luis Kuzma

Universidade Estadual do Centro-Oeste

http://lattes.cnpq.br/3541870715752296

edson.kuzma@gmail.com

\section{Edinéia Lopes}

Universidade Estadual do Centro-Oeste

http://lattes.cnpq.br/8718659230277867

edilopes.adm@gmail.com

Luis Paulo Gomes Mascarenhas

Universidade Federal do Paraná

http://lattes.cnpq.br/4187937070880705

luismk@gmail.com

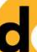

DOI: 10.6008/SPC2179-6858.2016.001.0011
Received: 13/11/2015

Approved: 24/11/2015

\author{
Raquel Dorigan de Matos \\ Universidade Federal do Paraná \\ http://lattes.cnpq.br/1242794030522878 \\ rdmatos@irati.unicentro.br \\ Sérgio Luis Dias Doliveira \\ Universidade Federal do Paraná \\ http://lattes.cnpq.br/6877990196326427 \\ sldd@uol.com.br
}

Referencing this:

KUZMA, E. L.; LOPES, E.; MASCARENHAS, L. P. G.; MATOS, R. D. DOLIVEIRA, S. L. D.. Preferência dos investidores em relação ao perfil econômico-financeiro das empresas participantes do ISE: revisão sistemática. Revista Ibero-Americana de Ciências Ambientais, v.7, n.1, p.124-141, 2016. DOI: http://doi.org/10.6008/SPC2179$\underline{6858.2016 .001 .0011}$ 


\section{INTRODUÇÃO}

O surgimento da sustentabilidade é marcado na década de 50, segundo Ribeiro Neto, Tavares e Hoffman (2008) pela exploração dos recursos naturais, caracterizada pelo uso sem a preocupação com a geração de resíduos, de modo que o costume adotado pelos indivíduos era diluir e dispersar. Além disso, a partir de 1960, com o aumento do número de indivíduos e consequentemente do consumo, surge a preocupação com a escassez dos recursos até então abundantes.

Esse dilema passou a fazer parte das pautas do setor empresarial, um assunto em constante desenvolvimento, a preocupação com os recursos naturais e o desenvolvimento sustentável. Dessa forma, o presente estudo traz definições e discussões sobre a gestão e a sustentabilidade corporativa diante de um aspecto geral das empresas, bem como as estratégias utilizadas no que diz respeito à produção consciente por parte das organizações. Entretanto, o posicionamento estratégico da empresa está diretamente ligado às iniciativas sustentáveis a partir de algumas diretrizes existentes, como a econômica, ambiental e social, presente em grande parte das corporações.

As empresas estão inseridas em um ambiente competitivo, de modo que os consumidores influenciam no método de gestão das empresas e acabam tendo poder de interferência nas ações empresariais. Diante disso, surgem empresas concorrentes em busca de vantagens competitivas, e a partir disso, o tema também trata de práticas sustentáveis voltadas para a imagem da empresa, resultando no desenvolvimento das mesmas a partir de indicadores de rentabilidade e lucratividade empresarial.

As empresas apresentam indicadores de rentabilidade e lucratividade corporativa que asseveram a compreensão das finanças empresariais, possibilitando aos gestores otimizarem as decisões sobre orçamento de capital, estrutura de capital e administração do capital de giro, que são essenciais à boa condução e manutenção da saúde financeira de uma organização (ROSS; WESTERFIELD; JORDAN, 2009). A análise desses indicadores possibilita verificar o desempenho histórico da companhia, de modo que ações possam ser planejadas com o intuito de redução do impacto das imprevisibilidades de mercado e das flutuações nas preferências de consumidores (SOUZA et al., 2014).

Os indicadores são indispensáveis, pois têm a função de prover os usuários de informações relevantes sobre as operações de investimento, financiamento e planejamento financeiro. Diante disso, tendo como objetivo estimular a inserção de práticas sustentáveis nas empresas, surgiram também os indicadores de desempenho em sustentabilidade empresarial, sendo o balanço social, relatório GRI de sustentabilidade, padrões de classificação de responsabilidade social e as carteiras hipotéticas de investimento em ações de desempenho sustentável, bem como o índice de sustentabilidade empresarial (ISE), tratado no decorrer do trabalho.

Portanto, o objetivo desta pesquisa é analisar a preferência dos investidores em relação ao perfil econômico-financeiro das empresas participantes do Índice de Sustentabilidade Empresarial da BM\&F Bovespa (ISE) no que diz respeito ao desenvolvimento de ações com foco em sustentabilidade. 
Assim sendo, a presente pesquisa busca identificar se as empresas que trabalham com a gestão sustentável têm um maior desenvolvimento no que diz respeito à imagem da empresa, valorização e aumento dos índices econômico e financeiro em relação às demonstrações contábeis, bem como à demanda de clientes e investidores.

\section{REVISÃO TEÓRICA}

\section{Gestão e Sustentabilidade Corporativa}

As empresas utilizam sua escala de produção visando lucratividade através da exploração de recursos naturais, consequentemente elevando a quantidade de resíduos. Dessa forma, obtém a importância de estudos e de investimentos na gestão sustentável. A definição de sustentabilidade e suas práticas estão cada vez mais presentes na gestão corporativa. Em um sentido amplo, pode-se definir esse termo como sendo a busca pelo cuidado com a qualidade dos sistemas ambientais e sociais. A sustentabilidade está relacionada com a quantidade máxima consumida em determinado período pela sociedade, de modo que no próximo período seja possível consumir o mesmo montante, isto é, permaneça inalterada a capacidade de produção e consumo (ALMEIDA, 2005).

Entretanto, Raupp (2010) informa a existência de diversos conceitos sobre a sustentabilidade, variando sob a ótica do escritor, isto é, alguns destacam para o âmbito ambiental, sendo considerada como a manutenção dos ecossistemas, como também sob o ponto de vista organizacional, considerando a capacidade de manter-se lucrativa e aceita pelos stakeholders.

A vida humana necessita da disponibilidade dos recursos naturais para sua subsistência. A partir da década de 60 , começou um movimento mundial no sentido de se promover estratégias voltadas à conservação e preservação do meio ambiente (LIMA; JÁCOME; PEDROSO, 2011). Entretanto a sustentabilidade só adquiriu a devida importância a partir do ano de 1987, no momento em que a Comissão Mundial sobre Meio Ambiente e Desenvolvimento das Nações Unidas, utilizou-o no relatório conhecido como Brundtland (CLARO; AMÂNICO, 2008).

Em 1990, as empresas começaram a investir na qualidade total e nos cuidados com a racionalização dos recursos, também destacando as questões ambientais, as quais a partir do ano 2000 foram acrescentadas nas agendas governamentais, bem como organizacionais e comunitárias (RIBEIRO NETO; TAVARES; HOFFMAN, 2008).

O posicionamento estratégico da empresa em relação ao gerenciamento dos impactos socioambientais relacionados à sua atividade produtiva representa um importante aspecto a ser analisado. (KNEIPP et al., 2013). Dessa forma, Jappur et al (2007) cita que a sustentabilidade corporativa trata do compromisso empresarial para com o desenvolvimento sustentável, que pode ser desenvolvido com base nas diretrizes preconizadas pelo World Business Council for Sustainable Development (WBCS), ou seja, nas 
três dimensões que delimitam o conceito de sustentabilidade corporativa, sendo a econômica, a ambiental e a social.

O autor ainda propõe os seguintes métodos: Responsabilidade Social Corporativa (RSC); Governança Corporativa; Ecoeficiência; Análise do Ciclo de Vida (ACV); Emissão Zero (ZERI); Sistemas de Gestão Certificáveis (SGC); Produção Mais Limpa; e os Relatórios de Sustentabilidade Corporativa - Global Reporting Initiative (GRI).

A partir da década de 90, houve a disseminação da certificação da série de normas ISO 9.000 e ISO 14.000. Porém, essa certificação não garante que as organizações sejam sustentáveis, pois o que promoverá isso será o nível do desempenho dos indicadores produzidos por estes sistemas (JAPPUR et al., 2007).

Portanto, as empresas que adotam práticas de gestão sustentáveis passam por grandes mudanças nos seus processos organizacionais, bem como no modo de se relacionar com os vários grupos de interesses (stakeholders). Por exemplo, para fazer parte de uma carteira de um determinado indicador de sustentabilidade a empresa deve incorporar os compromissos fundamentais e voluntários em relação à sustentabilidade, além de sua ampla divulgação e transparência. Deve também avaliar os impactos e riscos que o consumo e a utilização dos produtos fabricados por ela podem causar aos indivíduos e à sociedade. Deve incluir em sua gestão, critérios de governança corporativa, tais como, a criação de uma estrutura de gestão e de conselho de administração que estejam alinhados com os interesses dos acionistas (DIAS; BARROS, 2008)

Comunidades, governo, Organizações Não Governamentais (ONG's), seguradoras e investidores cobram processos limpos, bem como selecionam produtos e com processos que geram menor impacto negativo à sociedade. Dessa forma, essas condições acabam resultando em pressões sobre todas as operações e produtos das empresas, estabelecendo conflitos entre visões e valores distintos, bem como a competitividade entre empresas (ZAGO; MENDES, 2007).

\section{Competitividade e Sustentabilidade}

A sustentabilidade corporativa deve incluir, entre seus objetivos estratégicos, o cuidado com o meio ambiente, o bem-estar das partes interessadas e a constante melhoria da sua própria reputação (JAPPUR et al., 2007). A partir disso, nota-se que as corporações investem em gestão sustentável não apenas pela busca da preservação dos recursos naturais, ambientais e sociais, mas também como uma estratégia de marketing institucional da organização, ou seja, a melhoria da reputação corporativa, como citou Jappur, bem como, destaque e vantagem competitiva em meio à concorrência.

A população em geral está aumentando a sua consciência em relação à sustentabilidade, e procura cada vez mais utilizar produtos e serviços saudáveis. A prática de diferenciar produtos pelo desempenho ambiental está atraindo empreendedores para esse novo segmento, utilizando de selos verdes como um indicador sustentável. Essas ações resultam como diferencial de produtos e serviços como critério definidor 
das escolhas por parte dos consumidores na hora de realizar uma compra, bem como, a oferta de ações a investidores (BARBIERI, 2007).

Os mecanismos indutores de mercado têm contribuído para que as empresas assumam maior compromisso com o desenvolvimento sustentável, a partir de ações em bolsas de valores, adesão aos programas e certificações ambientais, fazendo com que estas se tornem cada vez mais competitivas no mercado. (ENRÍQUEZ; DRUMMOND, 2007 apud KNEIPP et al., 2013).

Esterhuizen, Rooyen e D'haese (2008) apud Soares e Petrini (2013) descrevem que a competitividade é a habilidade de uma organização competir com sucesso, buscando um crescimento sustentável, obtendo, assim, sob o menor custo de oportunidade, maiores retornos sobre os recursos empregados. Para Chikán (2008) apud Soares e Petrini (2013) a competitividade é a sua capacidade de atender às necessidades de seus clientes e ter lucro. É também a capacidade econômica de garantir aumento do bem-estar dos cidadãos, alinhado a capacidade de manter a produção ao longo do tempo.

Dessa forma, a precisão de enfoque da sustentabilidade e da vantagem competitiva está no curto e no longo prazo, sendo fatores decisivos para a sobrevivência da empresa, gestão sustentável duradoura e crescimento da mesma com lucratividade. Diante da análise, os indicadores de governança têm se disseminado nos mercados de ações, visando prover aos investidores maiores níveis de informação sobre os ativos. Portanto, como cita Cavalcante et al. (2007) esperam-se impactos positivos sobre o desempenho corporativo, pois os critérios que compõem os índices de governança devem garantir aos investidores menores níveis de incerteza.

Enfim, a associação entre estratégia social e vantagem competitiva é vista através da influência direta dos elementos: reputação e imagem, retenção de clientes e funcionários, desempenho econômico, ambiental e social, tornando esses elementos raros e valiosos para que as empresas possam obter vantagens competitivas (SOARES; PETRINI, 2013). Esse debate nos leva a um dos objetivos do estudo, no sentido de contrapor lucratividade e responsabilidade socioambiental, dando origem à verificação de empresas socialmente responsáveis, e em contrapartida, a lucratividade da mesma a partir dessas estratégias.

\section{Indicadores de Rentabilidade e Lucratividade Corporativa}

As decisões tomadas no campo da gestão empresarial recebem forte influência da necessidade de obtenção de desempenhos satisfatórios em diversos aspectos, sobretudo em virtude de geração de retorno sobre os investimentos dos sócios e acionistas, notoriamente representado pela lucratividade. Empresas que remuneram de forma suficientemente aceitável os recursos despendidos pelos investidores, além de manterem uma carteira fixa e regular de fundos, possibilita a atração de mais investidores, de modo que o potencial de competição da empresa frente suas concorrentes seja elevado (NUNES et al., 2010). Na perspectiva de autores que consideram relevante a contribuição da teoria econômica neoliberal (SOUZA; LARA, 2012), que corrobora com o pensamento econômico clássico de Friedman (1988), o lucro é uma das 
principais medidas diretas de mensuração da eficácia das empresas, em relação à ótica dos acionistas. No entanto, ela não é a única a ser considerada na avaliação de desempenho empresarial.

A literatura sobre finanças corporativas aborda a avaliação de desempenho empresarial sob a perspectivada maximização da riqueza dos acionistas (DAMODARAN, 2004; ROSS; WESTERFIELD; JORDAN, 2009). Entretanto, somente o retorno financeiro sobre os investimentos não caracteriza, de modo abrangente e relevante, a potencialidade de crescimento e sustentação de uma empresa em médio e longo prazo (HART; MILSTEIN, 2004). Num ambiente macroeconômico, condicionado pela constante transformação das relações estabelecidas entre parceiros comerciais e das preferências dos consumidores, a sensibilidade ao meio social deve ser considerada como um fator de posicionamento estratégico.

No embasamento das decisões voltadas à dimensão econômico-financeira das entidades empresariais, de investimento e alocação dos recursos próprios ou de terceiros, que garantem a continuidade das operações de produção e circulação de bens e mercadorias, estão as informações de cunho contábil e financeiro. De acordo com Favaro e Rover (2012), a leitura e análise das demonstrações contábeis, que são o principal instrumento que evidencia informações de natureza financeira, têm como objetivos examinar e avaliar o comportamento de uma empresa sobre os aspectos econômico-financeiros. Essas demonstrações contábeis apresentam um conjunto de informações que refletem a situação empresarial em um período determinado, além da elaboração de projeções ou planejamentos a respeito da disposição de recursos. O referido autor ainda acrescenta que a análise desses indicadores, pelo gestor financeiro, pode ser configurada como um instrumento relevante na compreensão do valor da empresa.

Conforme afirma Britto (2014), das três decisões principais que permeiam o planejamento financeiro das empresas, as duas primeiras fazem referência a ações de longo prazo, que dizem respeito ao orçamento de capital e à estrutura de capital. O orçamento de capital considera a alocação dos recursos obtidos pela empresa em seus diversos setores produção, de modo a garantir, numa perspectiva temporal, o uso dos mesmos de modo otimizado (ASSAF NETO, 2007). A estrutura de capitais se refere à arrecadação dos recursos, que são originários de duas fontes principais: capitais próprios e de terceiros. Os capitais próprios são oriundos das operações da própria empresa, pela geração de lucro e acumulação dos mesmos para reinvestimento nas operações de produção, enquanto os capitais de terceiros se remetem a fontes externas, sobretudo pela captação de novos investidores e venda de novas ações (MATARAZZO, 2007). A terceira decisão, que se refere à administração do capital de giro, é associada à saúde financeira da empresa em curto prazo. São relacionadas, neste segmento, as operações de planejamento tático, realizadas num período de tempo reduzido, ligadas à circulação direta das mercadorias (ASSAF NETO, 2007). Neste contexto, para que as decisões supramencionadas possam ser tomadas, um leque de instrumentais é requerido, entre eles, os indicadores financeiros.

Os indicadores financeiros fundamentam-se no cálculo e na interpretação de índices extraídos das demonstrações contábeis, sobretudo do balanço patrimonial e da demonstração de resultados. Considerando a complexidade e dinâmica das estruturas de mercado e o aspecto interno da empresa, o emprego desta análise possibilita que os gestores, acionistas e demais interessados possam tomar decisões 
acerca do desempenho da empresa em determinado período (GITMAN, 2004). A leitura dessas demonstrações contábeis evidencia a situação que a empresa apresenta, de modo que as decisões assumidas sejam mais assertivas e com menor margem de risco assumido.

As Demonstrações Contábeis são o conjunto de informações, sobre a situação e as movimentações financeiras de uma entidade empresarial, que devem ser obrigatoriamente divulgadas por empresas de capital aberto. Os ciclos de divulgação devem ser periódicos, em conformidade com a Lei 6.404/76, que rege esse aspecto no caso da administração das sociedades por ações, estabelecendo a prestação de contas para os sócios e acionistas, e de maneira geral para a sociedade. A prestação anual de contas é composta pelo Relatório da Administração, pelas Demonstrações Contábeis e pelas notas explicativas que as acompanham, o Parecer dos Auditores Independentes e o Parecer do Conselho Fiscal (NASCIMENTO et al., 2009).A Lei 11.638/07, que complementou a lei supracitada, estendeu também às sociedades de grande porte, deliberações relativas à elaboração e publicação de demonstrações contábeis, dispondo sobre os requisitos de qualificação de entidades de estudo e divulgação de princípios, normas e padrões de contabilidade e auditoria, como Organizações da Sociedade Civil de Interesse Público (ALIGLERI, 2011).

O desenvolvimento de leituras e interpretações das demonstrações contábeis constitui-se em uma ferramenta fundamental na geração de informações sobre o desempenho, a situação econômico-financeira e a gerenciadas empresas (ASSAF NETO, 2007). As demonstrações, do ponto de vista da gestão, são importantes para a descrição da situação financeira das organizações e configuram-se, portanto, numa ferramenta de auxílio no processo de tomada de decisões.

O entendimento da estrutura contábil, sobretudo pela configuração apresentada pelas demonstrações financeiras, viabiliza o desenvolvimento de avaliações mais detalhadas do perfil da empresa (MARQUES; COLARES; MAIA, 2010). O processo de análise demanda a existência de informações que reflitam um cenário mais próximo possível da realidade, uma vez que decisões tomadas com base em dados não confiáveis distancia a possibilidade de acerto.

Assim sendo, Maia, Nossa e Nossa (2012) asseveram que a análise das demonstrações contábeis, elaboradas com intenso rigor e em pareamento com a real contingência, propicia a avaliação do patrimônio da empresa. Enquanto ferramenta de elaboração de relatórios gerenciais fornece a avaliação do resultado econômico e financeiro da organização, num cenário estático ou não e em diversos períodos, apresentandose como uma determinante na comparação entre os resultados realizados e os planejados, podendo ser adotada como um suporte para ações que melhorem seu desempenho numa perspectiva futura.

Para Assaf Neto (2007) e Matarazzo (2007), as técnicas mais comuns de análise baseiam-se na apuração de indicadores econômico-financeiros, os quais podem ser subdivididos em quatro grupos: índice de liquidez, atividade, endividamento e estrutura de rentabilidade. Estes instrumentos analisam grupos de contas, objetivando a mensuração dos diferentes aspectos ligados à situação financeira estudada. 


\section{Indicadores de Desempenho em Sustentabilidade Empresarial}

A tendência de investimento em empresas que desenvolvem atividades ligadas à sustentabilidade é global, pois empresas que têm sua imagem associadas ao desenvolvimento sustentável, na busca do equilíbrio da atividade antrópica com o meio natural, são mais preparadas para enfrentar riscos e instabilidades econômicas, sociais e ambientais (RUFINO et al., 2014). Em especial no Brasil, essa tendência toma maior força com as ações da BM\&F Bovespa, além de outras instituições empresariais ou entidades ligadas à sociedade civil organizada, que fomentam a adoção de atitudes mais sensíveis às demandas sociais.

A mensuração das ações voltadas à sustentabilidade no meio empresarial, por meio de índices de sustentabilidade, tem por objetivo evidenciar ao mercado, aos analistas e aos indivíduos em geral, uma referência em termos de produtos financeiros, que atribui uma qualificação ao desempenho das companhias que gerenciam seus negócios em conformidade com a sustentabilidade e responsabilidade socioambiental (MACHADO; MACHADO, 2008). Os diversos públicos interessados necessitam do acompanhamento de tais ações, sobretudo no caso dos investidores, que podem tomar conhecimento do posicionamento das organizações que recebem seus recursos.

Os índices de sustentabilidade são, portanto, subsídios que possibilitam aos stakeholders a construção de uma análise, ainda que parcial, das ações empresariais. Estes indivíduos são considerados como partes interessadas aos assuntos pertinentes à empresa, assumindo o papel de atores sociais que tomam para si algum tipo de risco direto ou indireto perante a sociedade (MATARAZZO, 2007). Entre os indivíduos envolvidos neste relacionamento de solidariedade para com o desempenho econômico-sócioambiental da empresa estão os acionistas, colaboradores, clientes, fornecedores, comunidade, credores, governo e organizações não governamentais, que são incumbidos do acompanhamento do desenvolvimento e da perenidade das ações empresariais com foco em sustentabilidade.

Assim sendo, o mercado financeiro, que acompanha o movimento de adesão empresarial ao desenvolvimento sustentável, entende esse movimento como um compromisso permanente coma redução de impactos relacionados à exploração do meio natural e ao inter-relacionamento entre os indivíduos na produção das relações sociais, por meio das instituições financeiras. Os programas de mudanças institucionais, a composição de indicadores, a classificação de fundos de investimentos socialmente responsáveis (FONTOURA; BORSATO; BORSATO, 2013), são algumas dessas formas de acompanhamento.

\section{Carteiras Hipotéticas de Investimento em Ações de Desempenho Sustentável}

As empresas que têm suas ações negociadas em Bolsa de Valores podem estimular a preferência dos investidores em potencial por meio de padrões de classificação compostos pelas chamadas carteiras hipotéticas de investimento. O critério base para inclusão das mesmas neste quadro é, além de serem sociedades de capital aberto, investirem e fomentarem ações voltadas à sustentabilidade e à gestão de negócios pautando para o elemento social e ambiental. Entre os vários os índices utilizados, o mais conhecido 
e utilizado é o Índice Dow Jones de Sustentabilidade - DJSI, que é considerado referência para entidades gestoras de recursos, sobretudo nos investimentos em ações negociadas na bolsa de Nova lorque (NASCIMENTO et al., 2009). O DJSI analisa organizações com performance financeira positiva e que apresentem gestão sustentável de seus recursos, no aspecto social e ambiental.

O Índice de Sustentabilidade Empresarial - ISE, que se assemelha ao Dow Jones, também mensura a atividade empresarial de organizações que negociam suas ações em Bolsa de Valores, e que atentem para a dimensão humana, representada pelas relações sociais, e para a dimensão natural, que evidencia preocupações com a esfera ambiental.

\section{Índice de Sustentabilidade Empresarial - ISE}

O mercado financeiro, que procura focar nas preferências dos investidores, passa a incentivar as empresas com práticas sustentáveis, que podem gerar valor para o investidor no longo prazo, estando mais preparadas para conduzir os riscos econômicos, sociais e ambientais. A criação de índices de mensuração estimula a competitividade das empresas, de modo que estas se empenhem no desenvolvimento de ações diferenciadas, em termos de sustentabilidade empresarial (BM\&FBOVESPA, 2012).

No contexto da dinâmica do mercado internacional, o primeiro índice de mensuração financeiro foi lançado em 1999, denominado Índice Dow Jones de Sustentabilidade (Dow Jones Sustainable Index - DJSI). Esse índice procura não apenas acompanhar o desempenho financeiro das empresas, mas também disponibilizar aos investidores informações precisas sobre o modelo de gestão e o compromisso das empresas com fatores éticos, ambientais e sociais (MARCONDES; BACARJI, 2010).

No Brasil, atendendo à expectativa lançada por acionistas e de acordo com os modelos internacionais, criou-se em 2005 o Índice de Sustentabilidade Empresarial - ISE. Num trabalho conjunto da BM\&F Bovespa e de demais instituições ligadas aos aspectos financeiros e de fomento às ações voltadas à sustentabilidade, este indicador foi criado como uma referência de investimento socialmente responsável no Brasil (BEATO; SOUZA; PARISOTTO, 2009). Tem por objetivo refletir o retorno de uma carteira composta por ações de empresas com reconhecido comprometimento com a responsabilidade social e a sustentabilidade empresarial, e atuar como promotor das boas práticas no meio empresarial brasileiro.

O ISE é composto por um Conselho Deliberativo, que é presidido pela Bovespa e que tem como parceiros instituições como o Instituto Ethos e o Ministério do Meio Ambiente, entre outras (SOUZA et al., 2014). A estas instituições cabem as funções de desenvolver o critério de avaliação, enviar questionários, calcular o índice e por fim, definir e aprovar as empresas selecionadas.

Este indicador tem como objetivo propiciar o estímulo de um ambiente de investimento compatível com as demandas de desenvolvimento sustentável da sociedade contemporânea e estimular a responsabilidade social corporativa, considerando aspectos de governança corporativa e sustentabilidade empresarial (BM\&F BOVESPA, 2012). As empresas tidas como sustentáveis e rentáveis são denominadas 
desta forma, como sendo aquelas com "investimentos socialmente responsáveis" - ISR. Os investidores são estimulados a investir seus recursos nessas empresas, com a perspectiva de geração de valor no longo prazo.

A seleção das empresas que podem compor a carteira do Índice de Sustentabilidade Empresarial é elaborada com base num questionário, enviado aquelas que apresentarem as seguintes características: ações entre as 200 mais líquidas da BM\&F BOVESPA, nos dozes meses anteriores à avaliação; negociadas, nesse período, em pelo menos $50 \%$ dos pregões; e que atendam aos critérios de sustentabilidade referenciados pelo Conselho do ISE. Dentre elas, até 40 entidades farão parte da carteira (BM\&F BOVESPA, 2012). O questionário-base de avaliação é composto por sete dimensões de análise, a saber: Econômico-Financeira, Governança Corporativa, Natureza do Produto, Mudanças Climáticas, Geral, Responsabilidade Social e Ambiental.

As 40 empresas com as melhores qualificações recebem o mesmo questionário, para garantir a confiabilidade das informações. Entretanto, considerando que pertencem a ramos de atuação diferentes, com dinâmicas diferentes de trabalho, são divididas em níveis de impacto, nos quais se determina ainda pesos diferentes para cada dimensão (MARCONDES; BACARJI, 2010). Muito embora a avaliação procure considerar as particularidades de cada setor econômico, a relação de busca de mensuração das questões voltadas aos aspectos da sustentabilidade é unânime em todas.

Conforme asseveram Marcondes e Bacarji (2010), a utilização do ISE como instrumento de aferimento das ações em sustentabilidade gerou um impacto positivo, sobretudo em relação ao estímulo das boas práticas de governança perceptíveis pelos investidores. O indicador, ao fomentar a adoção de posicionamentos mais conformes às demandas socialmente estabelecidas, credita confiabilidade à entidade, demonstrando ao mercado a sua seriedade em relação à responsabilidade socioambiental. Ademais, por meio da utilização dos questionários, possibilitou-se a instituição de um instrumento de aprendizagem contínua, no qual as empresas se esforçam para se enquadrar aos padrões exigidos (NOGUEIRA; GOMES, 2012). A instrumentalização do índice, enquanto ferramenta de gestão, proporcionou às empresas a oportunidade redefinir e redirecionar seus processos e procedimentos, como meio de adequação das práticas empresariais ao anseio do aspecto social e ambiental.

\section{METODOLOGIA}

Conforme o objetivo proposto, a presente pesquisa buscou analisar a preferência dos investidores em relação ao perfil econômico-financeiro das empresas participantes do Índice de Sustentabilidade Empresarial da BM\&F Bovespa (ISE) no que diz respeito ao desenvolvimento de ações com foco em sustentabilidade.

Desse modo, a obtenção de informações e variáveis sobre a temática central foi realizada através da análise sistemática, ou seja, uma revisão a partir de uma busca planejada com o intuito de responder o objetivo proposto, e que utiliza métodos explícitos e sistemáticos para identificar, selecionar, coletar e avaliar criticamente os estudos incluídos na revisão (CASTRO, 2001). 


\section{Universo e Amostra da Pesquisa}

Para investigar a preferência dos investidores no quesito que se refere ao perfil econômico-financeiro das empresas participantes do ISE da BM\&F Bovespa, foram utilizadas buscas de artigos acadêmicos científicos publicados entre 2005 e 2014. Foi utilizada a produção científica nos principais eventos dentro do campo das ciências administrativas, contábeis e afins a partir de buscas via base de dados ANPAD - Associação Nacional de Pós-Graduação e Pesquisa em Administração.

A coleta de dados teve início com a determinação das palavras-chaves, ou seja, as possíveis combinações que atendessem o objetivo da pesquisa. Após, os artigos foram selecionados nos seguintes eventos: Encontro da ANPAD (EnANPAD), Encontro de Administração da Informação (EnADI) e no Encontro de Estudos em Estratégia (3ES), Encontro de Marketing (EMA), Encontro de Administração, Política e Governança (EnAPG), Encontro de Estudos Organizacionais (EnEO), Encontro de Ensino e Pesquisa em Administração e Contabilidade (EnEPQ), Encontro de Gestão, Pessoas e Relações de Trabalho (EnGPR) e Simpósios.

Os descritores utilizados foram "BM\&F Bovespa" no qual se encontrou 20 artigos, "ISE" localizado com 05 artigos, "Bolsa de Valores" com 12 e "Sustentabilidade" com 186 artigos no título e no resumo dos mesmos. A leitura dos títulos e resumos dos 223 artigos foi realizada pelos autores, dessa forma filtraramse 37 artigos.

Diante do exposto, o próximo passo da coleta de dados foi selecionar os artigos conforme os critérios de inclusão e exclusão estabelecidos:

a. Em relação ao conteúdo: foram incluídos os artigos que apresentaram a temática central relacionados ao Índice de Sustentabilidade Empresarial (ISE) com o desempenho das empresas e interesse de investidores durante o período de 2005 a 2014.

b. Em relação ao tipo de artigo: foram considerados apenas os artigos com metodologia quantitativa das diversas áreas da administração, ciências contábeis e economia.

c. Em relação à língua: foram considerados somente artigos em português.

d. Critérios de exclusão: foram excluídos os artigos que não fazem relação com o Índice de Sustentabilidade Empresarial da BM\&F Bovespa, bem como as que não se enquadravam com práticas de estratégias sustentáveis.

Após critérios de seleção, chegou-se a 08 artigos, demonstrados no Quadro 01:

\begin{tabular}{|l|l|l|l|l|l|l|}
\hline \multirow{2}{*}{ BUSCA } & \multirow{2}{*}{ ANO DE PUBLICAÇÃO } & \multicolumn{4}{|c|}{ COMBINAÇÕES } & \multirow{2}{*}{ TOTAL } \\
\cline { 3 - 8 } & Bolsa de Valores & $\begin{array}{c}\text { BM\& } \\
\text { FBovespa }\end{array}$ & ISE & Sustentabilidade & \\
\hline ANPAD & $2005-2014$ & 1 & 1 & 3 & 3 & 8 \\
\hline
\end{tabular}

A leitura da revisão bibliográfica foi utilizada para o embasamento teórico desta pesquisa, bem como livros e sites. Já a revisão dos resultados e demais variáveis foram utilizadas para a análise quantitativa deste. 


\section{RESULTADOS E DISCUSSÃO}

Conforme os objetivos propostos e a metodologia de pesquisa utilizada, foram selecionados 08 estudos como sendo relevantes e de acordo com a problemática abordada. Todos os estudos tratam do Índice de Sustentabilidade Empresarial associados à possibilidade ou não de levantamento de desempenho econômico-financeiro. Ressalta-se que as empresas estudadas são, obrigatoriamente, de capital aberto, com suas ações negociadas na Bolsa de Valores de São Paulo (Bovespa). Os estudos selecionados são apresentados no Quadro 02.

Quadro 02: Apresentação dos estudos selecionados, conforme a proposta metodológica.

\begin{tabular}{|c|c|c|c|c|c|c|c|}
\hline AUTOR & $\begin{array}{c}\text { TÍTULO DO } \\
\text { ARTIGO }\end{array}$ & $\begin{array}{l}\text { OBJETIVO DE } \\
\text { PESQUISA }\end{array}$ & METODOLOGIA & $\begin{array}{c}\text { PERÍOD } \\
0\end{array}$ & $\begin{array}{c}\text { RELAÇÃO } \\
\text { INVESTIGADA }\end{array}$ & $\begin{array}{c}\text { POPULAÇÃ } \\
0\end{array}$ & RESULTADOS \\
\hline $\begin{array}{l}\text { MAIA; } \\
\text { NOSSA; } \\
\text { NOSSA (2012) }\end{array}$ & $\begin{array}{l}\text { Análise do } \\
\text { retorno anormal } \\
\text { de empresas } \\
\text { winners e losers } \\
\text { participantes ou } \\
\text { não do Índice de } \\
\text { Sustentabilidad } \\
\text { e Empresarial } \\
\text { (ISE): um estudo } \\
\text { empírico na } \\
\text { BM\&F Bovespa }\end{array}$ & $\begin{array}{l}\text { Investigar se há } \\
\text { diferenças nos } \\
\text { retornos } \\
\text { anormais das } \\
\text { empresas } \\
\text { winner e losers } \\
\text { listadas na } \\
\text { BM\&F Bovespa, } \\
\text { entre as } \\
\text { classificadas e } \\
\text { não classificadas } \\
\text { no ISE }\end{array}$ & $\begin{array}{l}\text { Quantitativa, } \\
\text { por classificação } \\
\text { em winner e } \\
\text { losers; } \\
\text { Regressão em } \\
\text { pooled; } \\
\text { Histograma } \\
\text { gráfico de } \\
\text { probabilidade } \\
\text { normal }\end{array}$ & $\begin{array}{l}2005 a \\
2010\end{array}$ & $\begin{array}{l}\text { ISE; Risco e } \\
\text { Retorno } \\
\text { financeiro }\end{array}$ & $\begin{array}{l}352 \\
\text { empresas }\end{array}$ & $\begin{array}{l}\text { Empresas que } \\
\text { sinalizam } \\
\text { responsabilidade } \\
\text { social corporativa } \\
\text { obtiveram uma } \\
\text { relação negativa } \\
\text { com o } \\
\text { endividamento e } \\
\text { o risco quando } \\
\text { comparadas com } \\
\text { aquelas que não } \\
\text { sinalizam, ou seja, } \\
\text { as melhores } \\
\text { empresas em } \\
\text { desempenho no } \\
\text { ISE de fato são } \\
\text { reconhecidas } \\
\text { pelo mercado da } \\
\text { BM\&F Bovespa }\end{array}$ \\
\hline GOIS (2014) & $\begin{array}{l}\text { Reputação } \\
\text { corporativa e } \\
\text { desempenho } \\
\text { empresarial } \\
\text { superior: uma } \\
\text { análise nas } \\
\text { empresas } \\
\text { listadas na } \\
\text { BM\&F Bovespa }\end{array}$ & $\begin{array}{l}\text { Investigar a } \\
\text { reputação } \\
\text { corporativa e o } \\
\text { desempenho } \\
\text { empresarial nas } \\
\text { empresas de } \\
\text { capital aberto } \\
\text { listadas na } \\
\text { BM\&F Bovespa, } \\
\text { tomando como } \\
\text { base a teoria da } \\
\text { sinalização com } \\
\text { pressuposto } \\
\text { teórico. }\end{array}$ & $\begin{array}{l}\text { Descritiva e } \\
\text { Quantitativa, } \\
\text { Mann-Whitney e } \\
\text { a Regressão } \\
\text { Linear Múltipla }\end{array}$ & $\begin{array}{l}2011 \text { e } \\
2012\end{array}$ & $\begin{array}{l}\text { Reputação } \\
\text { Corporativa; } \\
\text { Crescimento e } \\
\text { Sustentabilidad } \\
\text { e do } \\
\text { Desempenho } \\
\text { Empresarial e } \\
\text { BM\&F Bovespa } \\
\text { (ISE) }\end{array}$ & $\begin{array}{l}250 \\
\text { empresas }\end{array}$ & $\begin{array}{l}\text { Empresas com } \\
\text { desempenho } \\
\text { empresarial } \\
\text { superior, no } \\
\text { quesito de } \\
\text { sustentabilidade, } \\
\text { apresentam } \\
\text { melhor reputação } \\
\text { corporativa em } \\
\text { relação às demais }\end{array}$ \\
\hline $\begin{array}{l}\text { LUZ; SILVA; } \\
\text { COELHO } \\
(2008)\end{array}$ & $\begin{array}{l}\text { A influência da } \\
\text { divulgação do } \\
\text { Índice de } \\
\text { Sustentabilidad } \\
\text { e Empresarial } \\
\text { sobre o preço } \\
\text { das ações no } \\
\text { Brasil e nos } \\
\text { EUA: um estudo } \\
\text { de eventos nos } \\
\text { anos de } 2005 \text { a } \\
2007\end{array}$ & $\begin{array}{l}\text { Verificar se as } \\
\text { ações das } \\
\text { empresas após } \\
\text { a divulgação de } \\
\text { sua entrada } \\
\text { para a carteira } \\
\text { do ISE sofreram } \\
\text { valorização } \\
\text { significativa, de } \\
\text { acordo com a } \\
\text { teoria dos } \\
\text { stakeholders }\end{array}$ & $\begin{array}{l}\text { Quantitativo e } \\
\text { Descritivo, } \\
\text { Econométrico de } \\
\text { estudo de } \\
\text { eventos. }\end{array}$ & $\begin{array}{l}2005 a \\
2007\end{array}$ & $\begin{array}{l}\text { Indicador de } \\
\text { boas práticas de } \\
\text { sustentabilidade } \\
\text { empresarial e } \\
\text { ISE }\end{array}$ & 18 empresas & $\begin{array}{l}\text { Verificaram-se } \\
\text { retornos } \\
\text { anormais } \\
\text { positivos e } \\
\text { negativos médios } \\
\text { para o conjunto } \\
\text { das empresas que } \\
\text { entraram a } \\
\text { carteira do ISE. } \\
\text { Esses retornos } \\
\text { não obedeceram } \\
\text { a um padrão, pois } \\
\text { empresas que } \\
\text { entraram para o } \\
\text { ISE também } \\
\text { apresentaram } \\
\text { retornos } \\
\text { anormais médios } \\
\text { negativos. }\end{array}$ \\
\hline
\end{tabular}




\begin{tabular}{|c|c|c|c|c|c|c|c|}
\hline $\begin{array}{l}\text { MACHADO e } \\
\text { MACHADO } \\
(2008)\end{array}$ & $\begin{array}{l}\text { Retorno } \\
\text { acionário e } \\
\text { adesão ao } \\
\text { Índice de } \\
\text { Sustentabilidad } \\
\text { e Empresarial } \\
\text { da Bovespa: um } \\
\text { estudo de } \\
\text { eventos }\end{array}$ & $\begin{array}{l}\text { Averiguar se } \\
\text { após a } \\
\text { divulgação pela } \\
\text { Bovespa de que } \\
\text { a empresa fará } \\
\text { parte da } \\
\text { carteira ISE, o } \\
\text { preço de suas } \\
\text { ações sofre } \\
\text { alteração }\end{array}$ & $\begin{array}{l}\text { Exploratório } \\
\text { descritivo, } \\
\text { bibliográfica e } \\
\text { documental, } \\
\text { Estudo de } \\
\text { Eventos; } \\
\text { Regressão; } \\
\text { Teste de sinais }\end{array}$ & $\begin{array}{l}2005 a \\
2008\end{array}$ & $\begin{array}{l}\text { Eficiência de } \\
\text { mercado; preço } \\
\text { das ações; valor } \\
\text { das empresas e } \\
\text { desempenho do } \\
\text { ISE }\end{array}$ & 35 empresas & $\begin{array}{l}\text { Não há evidencias } \\
\text { de que o ingresso } \\
\text { das empresas no } \\
\text { ISE da Bovespa } \\
\text { contribui } \\
\text { significativament } \\
\text { e para a alteração } \\
\text { do preço das } \\
\text { ações, indicando } \\
\text { que o efeito } \\
\text { deste evento é } \\
\text { previsto pelo } \\
\text { mercado }\end{array}$ \\
\hline $\begin{array}{l}\text { CAVALCANTE; } \\
\text { BRUNI e } \\
\text { COSTA (2008) }\end{array}$ & $\begin{array}{l}\text { Sustentabilidad } \\
\text { e Empresarial e } \\
\text { valor da } \\
\text { empresa: um } \\
\text { estudo de } \\
\text { eventos no } \\
\text { mercado } \\
\text { brasileiro de } \\
\text { ações }\end{array}$ & $\begin{array}{l}\text { Analisar a } \\
\text { evolução do } \\
\text { preço das ações } \\
\text { que compõe o } \\
\text { Índice de } \\
\text { Sustentabilidad } \\
\text { e Empresarial } \\
\text { no período } \\
\text { situado em } \\
\text { torno de sua } \\
\text { data de criação }\end{array}$ & $\begin{array}{l}\text { Estudo de } \\
\text { eventos }\end{array}$ & 2005 & $\begin{array}{l}\text { Valoração do } \\
\text { preço de ações } \\
\text { e anúncio de } \\
\text { inclusão ao ISE }\end{array}$ & 20 empresas & $\begin{array}{l}\text { Não foi } \\
\text { identificada a } \\
\text { existência de } \\
\text { retorno anormal } \\
\text { acumulado } \\
\text { negativo, } \\
\text { indicando que a } \\
\text { adoção de } \\
\text { práticas de } \\
\text { sustentabilidade } \\
\text { não ocasiona a } \\
\text { redução de valor. } \\
\text { Não há evidências } \\
\text { estatisticamente } \\
\text { significativas } \\
\text { entre } \\
\text { desempenho } \\
\text { financeiro e a } \\
\text { adoção de } \\
\text { práticas } \\
\text { sustentáveis }\end{array}$ \\
\hline $\begin{array}{l}\text { REZENDE; } \\
\text { NUNES; } \\
\text { PORTELA; } \\
\text { NASCIMENTO } \\
\text {; SALVADOR e } \\
\text { TELLES (2007) }\end{array}$ & $\begin{array}{l}\text { Um estudo } \\
\text { sobre o } \\
\text { desempenho } \\
\text { financeiro do } \\
\text { Índice BOVESPA } \\
\text { de } \\
\text { Sustentabilidad } \\
\text { e } \\
\text { Empresarial }\end{array}$ & $\begin{array}{l}\text { Verificar se o } \\
\text { retorno do (ISE) } \\
\text { é semelhante } \\
\text { aos índices de } \\
\text { ações } \\
\text { convencionais } \\
\text { da Bolsa de } \\
\text { Valores de São } \\
\text { Paulo, como o } \\
\text { Índice Bovespa } \\
\text { (Ibovespa), } \\
\text { Índice Brasil } \\
\text { (IBrx) e o Índice } \\
\text { de Ações com } \\
\text { Governança } \\
\text { Corporativa } \\
\text { Diferenciada } \\
\text { (IGC) }\end{array}$ & Teste T & $\begin{array}{l}2005 a \\
2007\end{array}$ & $\begin{array}{l}\text { Desempenho } \\
\text { financeiro e ISE }\end{array}$ & $\begin{array}{l}100 \\
\text { empresas }\end{array}$ & $\begin{array}{l}\text { O índice de } \\
\text { sustentabilidade } \\
\text { empresarial não } \\
\text { possui melhor } \\
\text { retorno que } \\
\text { outros índices de } \\
\text { ações } \\
\text { considerados } \\
\text { convencionais, } \\
\text { por selecionarem } \\
\text { empresas } \\
\text { considerando o } \\
\text { conceito de } \\
\text { sustentabilidade } \\
\text { empresarial. }\end{array}$ \\
\hline $\begin{array}{l}\text { CAVALCANTE; } \\
\text { BRUNI e } \\
\text { COSTA (2007) }\end{array}$ & $\begin{array}{l}\text { Sustentabilidad } \\
\text { e Empresarial e } \\
\text { Desempenho } \\
\text { Corporativo: } \\
\text { Uma Análise do } \\
\text { Mercado } \\
\text { Brasileiro de } \\
\text { Ações }\end{array}$ & $\begin{array}{l}\text { Confrontar o } \\
\text { desempenho de } \\
\text { uma carteira } \\
\text { teórica formada } \\
\text { pelas ações que } \\
\text { compõem o } \\
\text { Índice de } \\
\text { Sustentabilidad } \\
\text { e Empresarial } \\
\text { (ISE) com o } \\
\text { desempenho } \\
\text { das carteiras } \\
\text { teóricas que } \\
\text { formam o Índice } \\
\text { Bovespa } \\
\text { (Ibovespa) e o } \\
\text { Índice Brasil } \\
\text { (IBrX) }\end{array}$ & $\begin{array}{l}\text { Comparação dos } \\
\text { retornos } \\
\text { acumulados, } \\
\text { retornos médios } \\
\text { e desvios padrão } \\
\text { do ISE, do } \\
\text { Ibovespa e IBrX; } \\
\text { Testes de } \\
\text { estacionariedad } \\
\text { e das séries }\end{array}$ & $\begin{array}{l}2005 \text { e } \\
2006\end{array}$ & $\begin{array}{l}\text { Índice de } \\
\text { Sustentabilidad } \\
\text { e Empresarial } \\
\text { (ISE); } \\
\text { Desempenho } \\
\text { econômico- } \\
\text { financeiro e } \\
\text { carteiras } \\
\text { teóricas de } \\
\text { mercado }\end{array}$ & $\begin{array}{l}345 \\
\text { empresas }\end{array}$ & $\begin{array}{l}\text { Não há evidências } \\
\text { de desempenho } \\
\text { superior do ISE } \\
\text { em relação ao } \\
\text { Ibovespa e ao } \\
\text { IBrX. Além disso, } \\
\text { o ISE revelou-se } \\
\text { mais volátil do } \\
\text { que esses dois } \\
\text { outros índices no } \\
\text { período } \\
\text { considerado. }\end{array}$ \\
\hline $\begin{array}{l}\text { DIAS e } \\
\text { BARROS } \\
(2008)\end{array}$ & $\begin{array}{l}\text { Sustentabilidad } \\
\text { e empresarial e } \\
\text { retorno ao } \\
\text { acionista: um }\end{array}$ & $\begin{array}{l}\text { Avaliar se o } \\
\text { ingresso das } \\
\text { empresas na } \\
\text { carteira do ISE } \\
\text { traz retornos }\end{array}$ & $\begin{array}{l}\text { Quantitativa; } \\
\text { Empírico } \\
\text { analítica; } \\
\text { Estatística do } \\
\text { Teste t }\end{array}$ & $\begin{array}{l}2005 \text { e } \\
2006\end{array}$ & $\begin{array}{l}\text { Reações de } \\
\text { mercado; } \\
\text { Desempenho no } \\
\text { ISE; }\end{array}$ & 27 empresas & $\begin{array}{l}\text { Existem retornos } \\
\text { anormalmente } \\
\text { positivos às datas } \\
\text { próximas ao } \\
\text { anúncio da }\end{array}$ \\
\hline
\end{tabular}




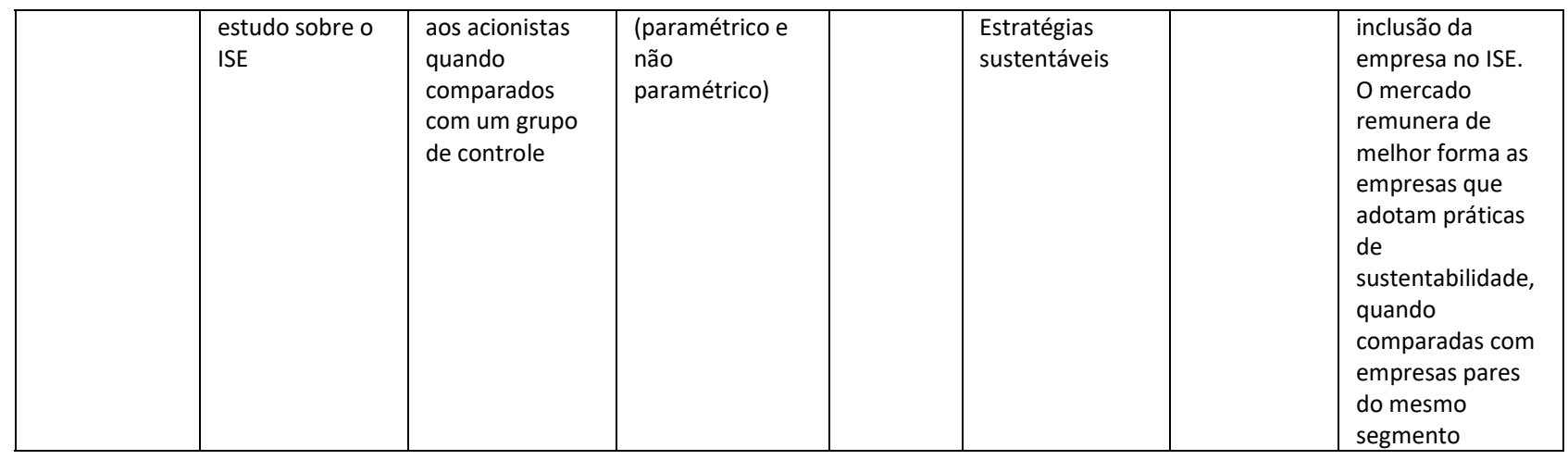

Conforme os estudos identificados na revisão sistêmica da literatura e dos dados apresentados nos artigos voltados à mensuração e abordagem do desempenho empresarial relacionado à prática sustentável, foram identificadas 08 pesquisas como sendo relevantes e enquadradas nos critérios apontados.

De acordo com Maia, Nossa e Nossa (2012), que buscaram investigar se há diferenças nos retornos anormais das empresas winner e losers listadas na BM\&F Bovespa, entre as classificadas e não classificadas no ISE, as empresas que sinalizam responsabilidade social corporativa obtiveram uma relação negativa com o endividamento e o risco de investimento, quando comparadas com aquelas que não sinalizam. Desse modo, evidenciou-se que as melhores empresas em desempenho no ISE de fato são reconhecidas pelo mercado da BM\&F Bovespa.

Na investigação de Góis (2014), que buscou conhecer a interação entre a reputação corporativa e o desempenho empresarial nas empresas de capital aberto listadas na BM\&F Bovespa, demonstrou-se que há uma relação positiva entre aquelas que adotam ações para suprir o quesito da sustentabilidade em comparação com as que não o fazem. Os resultados demonstraram que empresas que possuem uma maior estima e confiança do mercado, reputação corporativa na perspectiva contábil, conseguem auferir vantagem competitiva. Dessa forma, a reputação corporativa seria um recurso estratégico valioso com a capacidade de destacar as empresas perante as demais de seu setor, tendo como reflexo um desempenho empresarial acima da média.

No estudo de Dias e Barros (2008), a relação investigada foi de considerar se o ingresso das empresas na carteira do ISE traz retornos aos acionistas quando comparados com um grupo de controle. Os fatores analisados de reação do mercado frente à adoção de estratégias sustentáveis levaram à conclusão de que existem retornos anormalmente positivos às datas próximas ao anúncio da inclusão da empresa no ISE. O mercado remunera de melhor forma as empresas que adotam práticas de sustentabilidade, quando comparadas com empresas pares do mesmo segmento.

Em contraposição aos estudos que apresentam a inclusão das empresas no ISE como um fator que leva a uma melhor visibilidade de mercado, tem-se a pesquisa de Machado e Machado (2008), indicando que não há evidencias de que o ingresso das empresas no ISE da Bovespa contribui significativamente para a alteração do preço das ações, visto que o efeito deste evento é previsto pelo mercado. Entretanto, considerando a hipótese de mercado eficiente, isto não significa que o mercado de capitais não valoriza a questão de responsabilidade sócio-ambiental, mas sim que informações quanto à inclusão das empresas no 
ISE já estavam refletidas nos preços das ações. A inclusão de um direcionamento à sustentabilidade acarreta na incorporação de custos e despesas, além da valorização da empresa no mercado.

Da mesma forma, Luz, Silva e Coelho (2008) buscaram descrever se as ações e empresas após a divulgação de sua entrada para a composição da carteira do ISE sofreram valorização significativa. Verificouse que há a incidência de retornos anormais positivos e negativos médios, no quesito valorização, para o conjunto das empresas que entraram na carteira do ISE. Esses retornos não obedeceram a um padrão, pois empresas participantes do ISE também apresentaram retornos anormais médios negativos.

Contrapondo a lógica dos demais estudos realizados, Cavalcante, Bruni e Costa (2008) identificaram que a adoção de práticas sustentáveis não ocasiona redução de valor. Todavia, não há também evidências estatisticamente significativas entre desempenho financeiro e a adoção de práticas sustentáveis, neste contexto. O objetivo dessa análise foi de conhecer a evolução do preço das ações que compõe o Índice de Sustentabilidade Empresarial no período situado em torno de sua data de criação, considerando o ano anterior e posterior de sua instituição.

A pesquisa de Rezende et al. (2007) objetivou apontar se o retorno do Índice de Sustentabilidade Empresarial é semelhante aos índices de ações convencionais da Bolsa de Valores de São Paulo, como o Índice Bovespa (Ibovespa), Índice Brasil (IBrx) e o Índice de Ações com Governança Corporativa Diferenciada (IGC). Os resultados revelam que o Índice de Sustentabilidade Empresarial não possui melhor retorno que outros índices de ações considerados convencionais, por selecionarem empresas considerando o conceito de sustentabilidade empresarial. As evidências encontradas, por meio da utilização de testes estatísticos, demonstram que apesar do ISE possuir uma carteira teórica diferenciada, voltada ao tema social, ambiental e ético, o seu retorno é semelhante aos índices de ações convencionais.

No mesmo direcionamento, Cavalcante, Bruni e Costa (2007) buscaram confrontar o desempenho de uma carteira teórica formada pelas ações que compõem o Índice de Sustentabilidade Empresarial (ISE) com o desempenho das carteiras teóricas que formam o Índice Bovespa (Ibovespa) e o Índice Brasil (IBrX). Os resultados levantados apontam que não há evidências de desempenho superior do ISE em relação ao Ibovespa e ao IBrX. Além disso, o ISE revelou-se mais volátil do que esses dois outros índices no período considerado, visto que há indicações de que as carteiras retroagidas do ISE apresentaram melhor desempenho no período anterior à criação do índice. Assim sendo, não foi possível identificar um momento específico que marcasse a elevação percebida nos preços.

\section{CONSIDERAÇÕES FINAIS}

Ao longo deste trabalho, buscou-se analisar/conhecera preferência dos investidores em relação ao perfil econômico-financeiro das empresas participantes do ISE no que diz respeito ao desenvolvimento de ações com foco em sustentabilidade, entre os anos de 2005 a 2014.Foram levantados os principais estudos sobre a temática central a partir da revisão sistemática, sendo que os artigos selecionados estão compostos por empresas ligados à temática sustentabilidade. 
Em unanimidade, as pesquisas abordam a temática da sustentabilidade com enfoque no Índice Desempenho Empresarial (ISE) da Bolsa de Valores de São Paulo, que mensura as atividades e o desempenho das empresas de capital aberto que empreendem ações com foco na articulação dos aspectos econômico, social e ambiental. Aliado a esta percepção, aponta-se que a divulgação dos rankings de colocação das referidas organizações indica para a consideração de que não há evidências claras de que o índice pode ou não representar um incremento de sua competitividade frente às demais, sendo configurada como uma possibilidade de melhoria da visibilidade da mesma no mercado de ações.

Conforme observado, há estudos que sinalizam positivamente para a utilização do Índice de Sustentabilidade Empresarial como elemento de evidenciação de ações voltadas à sustentabilidade, ressaltando que sua adoção reverteu em benefícios positivos à empresa (MAIA; NOSSA; NOSSA, 2012; GOIS, 2014; DIAS; BARROS, 2008). Outros indicam que não podem ser aferidas vantagens relacionadas à melhor visibilidade da empresa no mercado pela simples utilização do Índice de Sustentabilidade Empresarial, pois as demonstrações revelam que, pela contraposição das tendências e preferências moldadas pelo sistema econômico, não há evidências que fundamentem tal posição (LUZ; SILVA; COELHO, 2008; MACHADO; MACHADO, 2008; CAVALCANTE; BRUNI; COSTA, 2008; REZENDE et al., 2007; CAVALCANTE; BRUNI; COSTA, 2007).

Portanto, dentre os08 estudos analisados, somente 03 evidenciaram que as empresas listadas no ISE são reconhecidas e se sobressaem perante as empresas não listadas. Dentre estas, muitas demonstram resultados positivos em relação à competitividade entre as empresas, valorização perante os investidores e clientes, e outras obtiveram retorno positivo já nas datas próximas aos anúncios de inclusão da empresa no ISE.

Diante do exposto, 05estudos apresentaram não possuir melhores retornos empresarias no que diz respeito ao ISE. Algumas empresas não obtiveram melhores retornos perante a comparação de outros índices listados na BM\&F Bovespa, outras somente não possuem melhores evidências ao adotarem práticas de gestão sustentáveis.

Os resultados encontrados apontam para uma contraposição entre o que usualmente a literatura preconiza e o que se evidenciou com a presente pesquisa. A sustentabilidade é colocada, quase que em unanimidade, como sendo um elemento que melhora a visibilidade da empresa frente suas concorrentes, pautando uma visão de que sua prática agrega valor à organização e, por conseguinte aos seus acionistas e proprietários (BRITTO, 2014; HART; MILSTEIN, 2004; KNEIPP et al., 2013; MARCONDES; BACARJI, 2010; SOARES; PETRINI, 2013; MARQUES; COLARES; MAIA, 2010). Entretanto, considerando o mercado de ações e a preferências dos investidores, que representam as dimensões abordadas nesta pesquisa, conclui-se que a adoção de práticas e utilização de indicadores voltados à sustentabilidade não são garantia de constituição de melhor visibilidade da empresa no mercado. Mas não se pode aferir, também, que ações com foco em sustentabilidade representem a formação potencial de elementos negativos, uma vez que a necessidade de atuação com base nas premissas do ser sustentável provém de um anseio socialmente estabelecido. 


\section{REFERÊNCIAS}

ALIGLERI, L. M.. A adoção de ferramentas de gestão para a sustentabilidade e a sua relação com os princípios ecológicos nas empresas. São Paulo: 2011. Tese (Doutorado em Administração), Universidade de São Paulo.

ALMEIDA, F.. Desenvolvimento sustentável, 2012-2015: visão, rumos e contradições. Rio de Janeiro: Elsevier, 2005.

ASSAF NETO, A.. Finanças Corporativas e Valor. São Paulo: Atlas, 2007.

BARBIERI, J. C.. Gestão ambiental empresarial: conceitos, modelos e instrumentos. 2 ed. atual e ampliada - São Paulo: Saraiva, 2007.

BEATO, R. S.; SOUZA, M. T. S.; PARISOTTO, I. R. S. Rentabilidade dos Índices de Sustentabilidade Empresarial em Bolsas de Valores: um estudo do ISE/BOVESPA. Revista de Administração e Inovação - RAI. São Paulo, v. 06, n. 03, set/dez. 2009.

BM\&F BOVESPA. Índice de Sustentabilidade Empresarial. O Valor do ISE. São Paulo, 2012.

BRITTO, W. S. F.. Análise do Conservadorismo Condicional nas Empresas cotadas na BM\&F BOVESPA que possuem ativos biológicos. XXXVIII Encontro da ANPAD, Rio de Janeiro, set. 2014.

CASTRO, A. A.. Revisão Sistemática e Meta-análise. 2015.

CAVALCANTE, L. R. M. T.; BRUNI, A. L.; COSTA, F. J. M.. Sustentabilidade Empresarial e Desempenho Corporativo: uma análise do mercado brasileiro de ações. XXXI Encontro da ANPAD, 2007.

CAVALCANTE, L. R. M. T.; BRUNI, A. L.; COSTA, F. J. M.. Sustentabilidade Empresarial e Valor da Empresa: um estudo de eventos no mercado brasileiro de ações. XXII Encontro da ANPAD, 2008.

CLARO, P. B. O.; CLARO, D. P.; AMÂNCIO, R.. Entendendo o conceito de sustentabilidade nas organizações. IN. Revista de Administração. São Paulo, v.43, n. 4, p.289-300, out-dez. 2008.

DAMODORAN, A.. Finanças Corporativas: teoria e prática. 2 ed. Porto Alegre: Bookman, 2004.

DIAS, E. A.; BARROS, L. A.. Sustentabilidade Empresarial e Retorno ao Acionista: um estudo sobre o ISE. XXXII Encontro da ANPAD, 2008.

FAVARO, L. C.; ROVER, S.. Índice de Sustentabilidade Empresarial (ISE): A Associação entre os Indicadores Econômico-financeiros e as empresas que compõem a carteira. V Congresso UFSC de Controladoria e Finanças \& Iniciação Científica em Contabilidade. Florianópolis, 2012.

FONTOURA, D. S.; BORSATO, J. M. S. L.; BORSATO, R. B.. Sustentabilidade em questão: os investidores reconhecem? XX Congresso Brasileiro de Custos. Uberlândia, nov. 2013.

FRIEDMAN, M.. Capitalismo e Liberdade. São Paulo: Nova Cultural, 1988.
GITMAN, L. J.. Princípios de Administração Financeira. 10 ed. São Paulo: Pearson Addison Wesley, 2004.

GÓIS, A. D.. Reputação Corporativa e Desempenho Empresarial Superior: uma análise das empresas listadas na BM\&F Bovespa. XXXVIII Encontro da ANPAD, 2014.

HART, S. L.; MILSTEIN, M. B.. Criando valor sustentável. Revista de Administração de Empresas - RAE Executivo, v. 03, n. 02, mai/jul. 2004.

JAPPUR, R. F.; CAMPOS, L. M. S.; HOFFMANN, V. E.; SELIG, P. M.. A Sustentabilidade Corporativa Frente às Diversas Formações de Cadeias Produtivas Segundo a Percepção de Especialistas. III Encontro de Estudos em Estratégia, 2007.

KNEIPP, J. M.; GOMES, C. M.; ROSA, L. A. B.; BICHUETI, R. S.. Práticas de Gestão para a Sustentabilidade e a Postura Estratégica de Empresas do Setor Mineral. VI Encontro de Estudos em Estratégia, 2013.

LIMA, A. K. T.; JÁCOME, A. C.; PEDROSA, F. J. A.. Educação Ambiental e Reciclagem: uma abordagem ao programa de reciclagem "não vai pelo ralo" da EMLUR de João Pessoa Paraíba. SEABRA, G.; MENDONÇA, I.. Educação ambiental: Responsabilidade para a conservação da sociobiodiversidade. João Pessoa: Editora Universitária da UFPB, 2011. V. 4.

LUZ, S. G.; SILVA, R. N. S.; COELHO, P. S.. A Influência da Divulgação do Índice de Sustentabilidade Empresarial sobre os Preços das Ações no Brasil e nos Estados Unidos: um estudo de eventos nos anos de 2005 e 2007. XXXII Encontro da ANPAD, 2008.

MACHADO, M. R. M.; MACHADO, M. A. V.. Retorno Acionário e adesão ao Índice de Sustentabilidade Empresarial da Bovespa: um estudo de eventos. XXXII Encontro da ANPAD. Rio de Janeiro, set. 2008.

MAIA, S. G. S.; NOSSA, V.; NOSSA, S. N.. Análise do Retorno Anormal das empresas Winners e Losers participantes ou não do Índice de Sustentabilidade Empresarial (ISE): um estudo empírico na BM\&F BOVESPA. XXXVI Encontro da ANPAD. Rio de Janeiro, set. 2012.

MARCONDES, A. W.; BACARJI, C. D.. ISE - Sustentabilidade no Mercado de Capitais. São Paulo: Report, 2010.

MARQUES, V. A.; COLARES, A. C. V.; MAIA, S. C.. Sustentabilidade e desempenho empresarial: uma comparação entre os indicadores de rentabilidade das empresas participantes do mercado de capitais. XVII Congresso Brasileiro de Custos. Belo Horizonte, nov. 2010.

MATARAZZO, D. C.. Análise Financeira de Balanços. 6 ed. São Paulo: Atlas, 2007.

MATIAS, C. A. B.. Finanças Corporativas de Longo Prazo: criação de valor com sustentabilidade financeira. São Paulo, Atlas, 2007. 
NASCIMENTO, S.; CASAGRANDE, M. H.; SOUZA, R. P. S.; GREUEL, M.; HEIN, N.. Índice de Sustentabilidade Empresarial (ISE): nível de evidenciação das informações econômico-financeiras das empresas de carnes e derivados. Revista Gestão Contemporânea. Porto Alegre, ano 06, n. 06, jan/dez. 2009.

NOGUEIRA, C. M. S.; GOMES, A. C. C.. Desempenho do Índice de Sustentabilidade Empresarial (ISE) sob a perspectiva do Retorno Ajustado ao Risco: sustentabilidade gera retorno? Revista Espaço Acadêmico, n. 131, abr. 2012.

NUNES, J. G.; TEIXEIRA, A. J. C.; NOSSA, V.; GALDI, F. C. Análise das Variáveis que Influenciam a Adesão das Empresas ao Índice BM\&F BOVESPA de Sustentabilidade Empresarial. Revista de Administração e Contabilidade da Unisinos. São Leopoldo, v. 7, n. 4, 2010.

RAUPP, W.. Trajetória humana e sustentabilidade. Porto Alegre: Editora Letral, 2010.

REZENDE, A. A. C.. Análise da Rentabilidade e Performance dos Investimentos Socialmente Responsáveis: um estudo empírico no mercado brasileiro. 40 simpósio FUCAPE de Produção Científica. Vitória, 2006.

REZENDE, I. A. C.; NUNES, J. G.; PORTELA, S. S.; NASCIMENTO, A. P. SALVADOR, N. TELLES, T. E. A. O.. Um estudo sobre o desempenho financeiro do Índice Bovespa de Sustentabilidade Empresarial, XXXI Encontro da ANPAD, 2007.

RIBEIRO NETO, J. B. M.; TAVARES, J. C.; HOFFMAN, S. C.. Sistemas de gestão integrados: qualidade, meio ambiente, responsabilidade social e segurança e saúde no trabalho. São Paulo: Editora Senac São Paulo, 2008
ROSS, S. A; WESTERFIELD, R. W.; JORDAN, B. D.. Princípios de Administração Financeira. 2 ed. São Paulo: Atlas, 2009.

RUFINO, M. A.; MAZER, L. P.; MACHADO, M. R.; CAVALCANTE, P. R. N.. Sustentabilidade e Performance dos indicadores de Rentabilidade e Lucratividade: um estudo comparativo entre os bancos integrantes e não integrantes do ISE da BM\&F BOVESPA. Revista Ambiente Contábil. João Pessoa, v. 06, n. 01, jan/jun. 2014.

SILVA, L. S.; MENEZES, E. M.. Metodologia da pesquisa e elaboração de dissertação/. - 4. ed. rev. atual. Florianópolis: UFSC, 2005.

SOARES, E. C.; PETRINI, M. C.. Competitividade Sustentável ou Sustentabilidade Competitiva: Ensaio Sobre as Bases Conceituais da Competitividade e Sustentabilidade. VI Encontro de Estudos em Estratégia, 2013.

SOUZA, F. S.; ZUCCO, A.; TOMÉ, I. M.; PEREIRA, R. S.. Análise do Índice de Sustentabilidade Empresarial - ISE: um estudo exploratório com o IBOVESPA. Connexio - Revista Científica da Escola de Gestão e Negócios, ano 4, edição especial, 2014.

SOUZA, T. G.; LARA, A. M. B.. Os fundamentos teóricometodológicos das Escolas Neoliberais do século XX: implicações nas políticas educacionais. IX Seminário de Pesquisa em Educação da Região Sul. 2012.

ZAGO, A. P. P.; MENDES, G. P.. Sustentabilidade Corporativa: o caso "Dow Jones Sustainability Index". XXXI Encontro da ANPAD, 2007. 